\title{
Synthesis and photophysical study of divalent complexes of chelating Schiff base
}

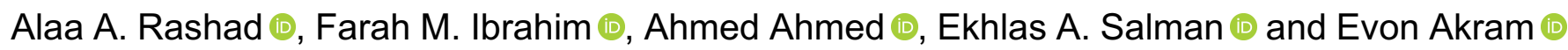 \\ Department of Chemistry, College of Science, Al-Nahrain University, Baghdad, Iraq
}

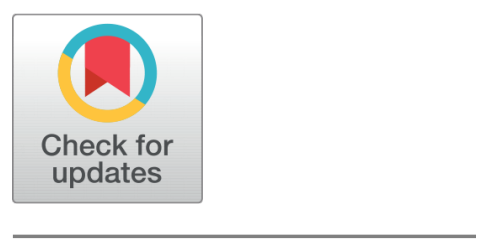

Received 06-10-2020

Revised 12-10-2020

Accepted 25-10-2020

Published 30-10-2020

\section{Corresponding Author}

Farah M. Ibrahim

farahtaha2016@gmail.com

Department of Chemistry, College of Science, Al-Nahrain University, Baghdad, Iraq

DOI https://doi.org/10.47419/ bjbabs.v1i01.27

\section{Pages: 5-17}

Distributed under the terms of the Creative Commons

Attribution-NonCommercial 4.0 International (CC BY-NC 4.0), which permits use for any non-commercial purpose, distribution, and reproduction in any medium, provided that the original work is properly cited.

Copyright: (C) 2020 Alaa A. Rashad, Farah M. Ibrahim, Ahmed Ahmed, Ekhlas A. Salman, Evon Akram

\section{ABSTRACT}

Background: Schiff base compounds derivative from 1,2,4-triazole, and their transition metal complexes play an essential role in coordination and bioinorganic chemistry due to biological and industrial applications.

Objectives: This work aims to prepare and characterize 1,2,4-triazole Schiff base and its complexes with a theoretical study, photophysical properties, and surface morphology for these complexes.

Methods: 1,2,4-triazole Schiff base prepared by condensation reaction between 4-Amino-3-mercapto-5-phenyl-4H-1,2,4-triazole and 2-hydroxy-1-naphthaldehyde, then Schiff base reacted with $\mathrm{Co}^{2+}, \mathrm{Ni}^{2+}$, and $\mathrm{Cu}^{2+}$ ions, the synthesized 1,2,4-triazole Schiff base, and its complexes were characterized by infrared spectra, magnetic susceptibility, conductivity measurements, photophysical properties, and surface morphology measured by atomic force microscopy. The practical results were reinforced with a theoretical study, using PM3 calculation and HyperChem program, for these Schiff base complexes.

Results: 1,2,4-triazole Schiff base act as a chelate ligand. The coordination has occurred through the oxygen of the phenolic group $\mathrm{O}-\mathrm{H}$ and the nitrogen of the imine group $\mathrm{N}=\mathrm{C}$ of Schiff base with divalent metal ions. Cobalt complex has a tetrahedral geometry, while the nickel and copper complexes have square planar geometries. The stability of all compounds was studied by calculating the energy gap by diffuse reflectance spectroscopy and theoretical calculations. Copper Schiff base is a more stable complex due to the lower value of the energy gap, and the copper Schiff base complex is more semiconductivity than the other complexes. Surface morphology, properties of chelating Schiff base ligand and its complexes measured by atomic force microscopy, cobalt Schiff base complex is higher roughness. The bond length of (-C=N-), (-C-O-),(M-O), and (M-N) are affected in the coordination with metal ions, the bond length of the square planar geometry more affected than tetrahedral geometry.

Conclusions: All compounds were prepared successfully, characterized, and photophysical properties were studied.

Keywords energy gap, morphology, triazole metal (II) complexes, triazole Schiff base

\section{OPEN ACCESS}




\section{INTRODUCTION}

Schiff bases are compounds prepared by Hugo Schiff via condensation of primary amines and carbonyl compounds; the products have an imine group. ${ }^{1}$ The literature has many published types of research on Schiff base complexes containing 1,2,4-triazole moiety which have antifungal, anticancer, antibacterial, and anti-inflammatory like non-steroidal anti-inflammatory drugs so that it can use in the treatment of communicable diseases, Candida infections, and Blastomyces dermatitidis. The biological activity of Schiff base increases by the coordination with transition metal ions. ${ }^{2-5}$ Besides, Schiff bases and its metal complexes act as anti-ureas agents, catalyze urea hydrolysis by ureases. ${ }^{6}$ The industrial field of the Schiff base is used as corrosion inhibitors. ${ }^{7,8}$

Recent studies focus on the preparation of new transition metal complexes of 1,2,4- triazole Schiff bases with their biological activity. Schiff bases complexes of triazole exhibit better biological activity than the free triazole derivatives and the geometry of these complexes suggested by different spectral analysis. ${ }^{9}$ The stable metal ions of the Schiff bases were synthesized and characterized by mass analysis, ${ }^{1} \mathrm{H}$ NMR, ultraviolet, infrared, and molar conductivity, the result of the antibacterial activity indicates that metal complexes show increases in activity compared to a free Schiff base ligand. ${ }^{10}$ Schiff base complexes were synthesized and characterized by analytical spectroscopy, chelation of Schiff base with metal ions occurs through the deprotonated phenolic group and azomethine group; therefore, octahedral geometry was suggested. The effect of these complexes on antibacterial was studied and showed the activity increases with complexation. ${ }^{11}$ Hexadentate Schiff base derivative from salicylaldehyde was reacted with Cr III, Fe III, Co III ions, and characterized by ${ }^{1} \mathrm{H} \mathrm{NMR},{ }^{13} \mathrm{CNMR}$ spectra, infrared, electronic spectra, elemental analysis, thermal analysis, conductivity, and magnetic susceptibility measurements, the metal ion was coordinated with Schiff base ligand through the oxygen of phenol, the nitrogen of imine group and oxygen of ether atoms to suggest octahedral geometry. The biological activity of hexadentate Schiff base derivative with its complexes was measured. ${ }^{12}$ The Schiff base derived from 1,2,4-triazole react with $\mathrm{Cu}^{2+}$ and $\mathrm{Zn}^{2+}$ ion using 1:2 (Metal: Ligand) mole ratio, These complexes were characterized by different chemical and physical technics so that $\mathrm{Cu}^{2+}$ and $\mathrm{Zn}^{2+}$ complexes have octahedral geometry, the antimicrobial activity of these complexes was measured. ${ }^{13}$ The presence of a Schiff base containing the 1,2,4-triazole in polystyrene film showed enhancing photostability for polystyrene against irradiation by ultraviolet light (14). $\mathrm{Co}^{2+}, \mathrm{Ni}^{2+}, \mathrm{Cu}^{2+}$, and $\mathrm{Zn}^{2+}$ complexes of 1,2,4-triazole Schiff bases were prepared using molar ratio 1:1 (ligand: metal), the structure of the Schiff bases and its metal complexes were characterized by different spectrometry, the ligand act as negative tridentate. From spectral studies and theoretical calculations the $\mathrm{Co}^{2+}, \mathrm{Ni}^{2+}$ complexes have octahedral geometry, $\mathrm{Cu}^{2+}$ complex has a square planar geometry, and tetrahedral geometry for $\mathrm{Zn}^{2+}$ complex. Also, these metal complexes have good anticancer activity against human breast cancer cell line compared to the free ligand. ${ }^{14}$

This work aims to prepare and characterize the Schiff base derivative from 1,2,4-triazole, then the Schiff base reacted with divalent metal ions, as well as the work involves theoretical 
study using PM3 calculation and HyperChem program, surface morphology, and photophysical properties of the prepared complexes.

\section{MATERIALS AND METHODS Chemicals and reagents}

The chemicals used have high purity. Ethanol (98\%), $\mathrm{CoCl}_{2}$ (99.9\%), $\mathrm{NiCl}_{2} \cdot 6 \mathrm{H}_{2} \mathrm{O}$ (99.8\%), and $\mathrm{CuCl}_{2} \cdot 2 \mathrm{H}_{2} \mathrm{O}$ (99.9\%) were purchased from Sigma-Aldrich. Sodium acetate (98.9\%) was used from Honeywell Fluka.

\section{Instrumentation}

All compounds were characterized by FTIR ALPHA spectrophotometer (Bruker Optics, Model Alpha), magnetic susceptibility balance by Johnson Mattey, which can be used for describing paramagnetic and diamagnetic materials. Molar conductivity measurements were carried by corning conductivity meter 220. The photophysical properties were measured by diffuse reflectance spectroscopy (Avantes DH-S-BAL-2048 UV-Vis) in a wavelength range of 230-1100 nm. The Surface Morphology properties measured by Atomic Force Microscopy (AFM), AFM analysis was used to scan, prop microscopy Angstrom advanced AA 2000 and a model used was contact mode, under normal atmospheric conditions.

\section{Selection of solvents}

In the solubility, ethanol was selected as the solvent for dissolving 1,2,4-triazole Schiff base, and its complexes.

\section{Preparation of 1,2,4-triazole Schiff base (SHL)}

Schiff base ligand (SHL) was prepared by condensation reaction of 4-Amino3-mercapto-5-phenyl-4H-1,2,4-triazole (1) $\quad(0.9 \mathrm{~g} / \quad 0.01 \mathrm{~mol}) \quad$ with 2-hydroxy-1naphthaldehyde $(2)(1.8 \mathrm{~g} / 0.01 \mathrm{~mol})$ in ethanolic solution $(100 \mathrm{ml}) 4-5$ drops of glacial acetic acid was added in $250 \mathrm{ml}$ round bottom flask, the mixture was refluxed for 8 hrs. The resulting solution left to cool, then the precipitate was filtered, and washed with ethanol and dried, yellowish powder (3) was identified by FTIR analysis, ${ }^{15-17}$ the synthesis of SHL was shown in Figure 1. 


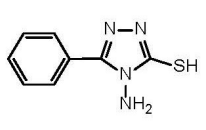

(1)

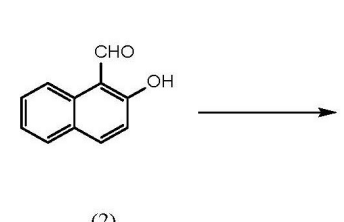

(2)

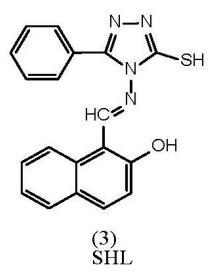

Figure 1 Preparation of SHL

\section{Preparation of divalent metal complexes}

A hot ethanolic solution of the SHL $(0.69 \mathrm{~g} / 0.02 \mathrm{~mol})$, was added to the ethanolic solution $(0.13 \mathrm{~g} / 0.23 \mathrm{~g} / 0.17 \mathrm{~g} ; 0.01 \mathrm{~mol})$ of $\mathrm{CoCl}_{2} ; \mathrm{NiCl}_{2} .6 \mathrm{H}_{2} \mathrm{O} ; \mathrm{CuCl}_{2} .2 \mathrm{H}_{2} \mathrm{O}$, respectively. Then sodium acetate $(0.5 \mathrm{~g})$ was added to the mixture to adjust the $\mathrm{pH}$ of the solution, after that reflux the reaction for $4 \mathrm{hrs}$. Then pouring the mixture into the $100 \mathrm{ml}$ distilled water to separate the product. Filter the suspended solid metal complex to collect it, washed with distilled water several times, and crystallization with a hot ethanol solution and place in the oven at $50^{\circ} \mathrm{C} .{ }^{13}$ The yield was $85 \%$.

\section{RESULTS AND DISCUSSION Infrared spectra}

The infrared frequencies of the SHL and its complexes are shown in Table 1. Schiff base has bands appear at $2520.0 \mathrm{~cm}^{-1}$ and $788.0 \mathrm{~cm}^{-1}$ due to $v \mathrm{~S}-\mathrm{H}$ and the $v \mathrm{C}=\mathrm{S}$, respectively, so that the tautomerism expected, this phenomena also appear in the spectra of the complexes that means thioamide group not involving in coordination with metal ions. The $v \mathrm{C}=\mathrm{N}$ imine band appears at $1618.33 \mathrm{~cm}^{-1}$ was shifted to a lower frequency in the SHL complexes; therefore, the coordination with metal ions through the nitrogen of the imine group occurred. Schiff base ligand has a $v \mathrm{O}-\mathrm{H}$ band at $3250.10 \mathrm{~cm}^{-1}$ due to the phenolic group, disappearing this band in SHL complexes, indicates the oxygen coordinated with the metal ion. Besides, $v \mathrm{C}-\mathrm{O}$ stretching vibrations in the SHL complexes appear at $1076.44 \mathrm{~cm}^{-1}$ shifted to longer wave numbers due to coordination. New bands at $(598.91-500.93) \mathrm{cm}^{-1}$ for $v \mathrm{M}-\mathrm{O}$ and (511.09-417.20) $\mathrm{cm}^{-1}$ for $v \mathrm{M}-\mathrm{N}$ appears in the lower wavenumber region. ${ }^{4,5,18}$

The magnetic moment of $\mathrm{Co} \mathrm{d}^{7}$ was 4.62 B.M.; therefore, the suggested geometry was tetrahedral due to paramagnetic properties. $\mathrm{Ni} \mathrm{d}^{8}$ has a magnetic moment zero due to diamagnetic properties; therefore, the square planar geometry was suggested. $\mathrm{Cu} \mathrm{d}^{9}$ has a magnetic moment 1.67 B.M. so that square planar geometry was proposed, ${ }^{19}$ the complexes showed non-electrolytic properties through the conductivity measurements using the DMF solvent, see Table 2 . 


\begin{tabular}{llll}
\hline \multicolumn{2}{l}{ Table 1 Infrared bands of SHL and its metal complexes, $\mathbf{c m}^{-1} \cdot$} \\
Compound & $v \mathbf{O}-\mathbf{H}$ & $v \mathbf{C}=\mathbf{N}$ & \\
SHL & 3250.10 & 1618.33 & 1076.44 \\
CoSHL & - & 1574.50 & 1143.73 \\
NiSHL & - & 1575.80 & 1144.43 \\
CuSHL & - & 1573.44 & 1103.01 \\
\hline
\end{tabular}

Table 2 Physical data of SHL and c omplexes.

\begin{tabular}{|c|c|c|c|c|}
\hline Compound & Colour & $\begin{array}{l}\text { Conductivity } \\
\text { solvent } \mu \text { s } / \mathrm{cm}\end{array}$ & Suggested formula & $\begin{array}{l}\text { Magnetic } \\
\text { moment, B.M. }\end{array}$ \\
\hline SHL & Yellow & - & $\mathrm{C}_{18} \mathrm{H}_{14} \mathrm{~N}_{4} \mathrm{SO}$ & - \\
\hline CoSHL & Greenish blue & 12 & $\mathrm{Co} \mathrm{C}_{36} \mathrm{H}_{26} \mathrm{~N}_{8} \mathrm{~S}_{2} \mathrm{O}_{2}$ & 4.620 \\
\hline NiSHL & Light green & 15 & $\mathrm{Ni} \mathrm{C}_{36} \mathrm{H}_{26} \mathrm{~N}_{8} \mathrm{~S}_{2} \mathrm{O}_{2}$ & Zero \\
\hline CuSHL & Green & 19 & $\mathrm{Cu} \mathrm{C}{ }_{36} \mathrm{H}_{26} \mathrm{~N}_{8} \mathrm{~S}_{2} \mathrm{O}_{2}$ & 1.68 \\
\hline
\end{tabular}

\section{Reflectance and band energy measurement}

The photophysical properties of SHL and its complexes were measured by diffuse reflectance spectroscopy DRS in the range $230-1100 \mathrm{~nm}$, see Figure 2. The electrons transition from the low spin (valence band) to the high spin (conductive band) to measure the band energy of the prepared complexes. ${ }^{20-22}$

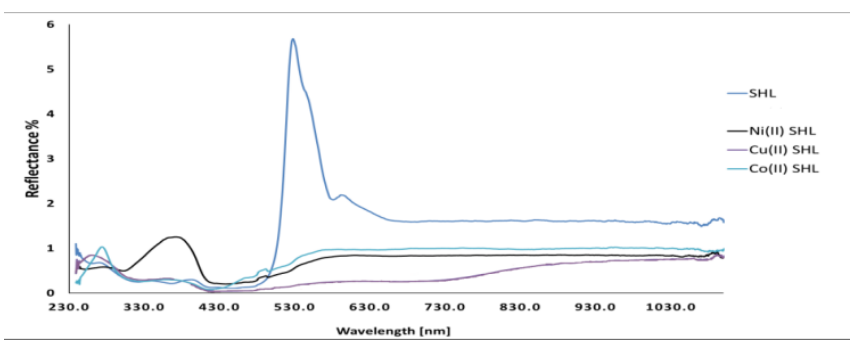

Figure 2 Diffuse reflectance spectra of SHL and complexes

The conductive properties of the complexes measured the band gaps from diffuse reflectance spectra using Kubelka-Munk theory. ${ }^{23}$ The plots of $\left[\mathrm{F}\left(\mathrm{R}_{\infty}\right) \mathrm{h} v\right]^{2}$ versus photon energy $(\mathrm{h} \nu)$ were used, and the intercept determines the band gaps value. Where $\mathrm{R}_{\infty}=$ sample reflection coefficient, $\lambda=$ absorption wavelength, $\mathrm{F}(\mathrm{R})$ : function, and photon energy: (he), see Figure 3

$$
\begin{aligned}
& F=\frac{\left(1-R_{\infty}\right)^{2}}{2 R_{\infty}} \ldots . . .(1) \\
& \alpha h \nu=C_{1}\left(h \nu-E_{g}\right)^{1 / 2} \\
& \alpha=F\left(R_{\infty}\right) \ldots . .(2) \\
& {\left[F\left(R_{\infty}\right) h \nu\right]^{2}=C_{2}\left(h \nu-E_{g}\right) \ldots . .(3)} \\
& h \nu=1240 / \lambda
\end{aligned}
$$



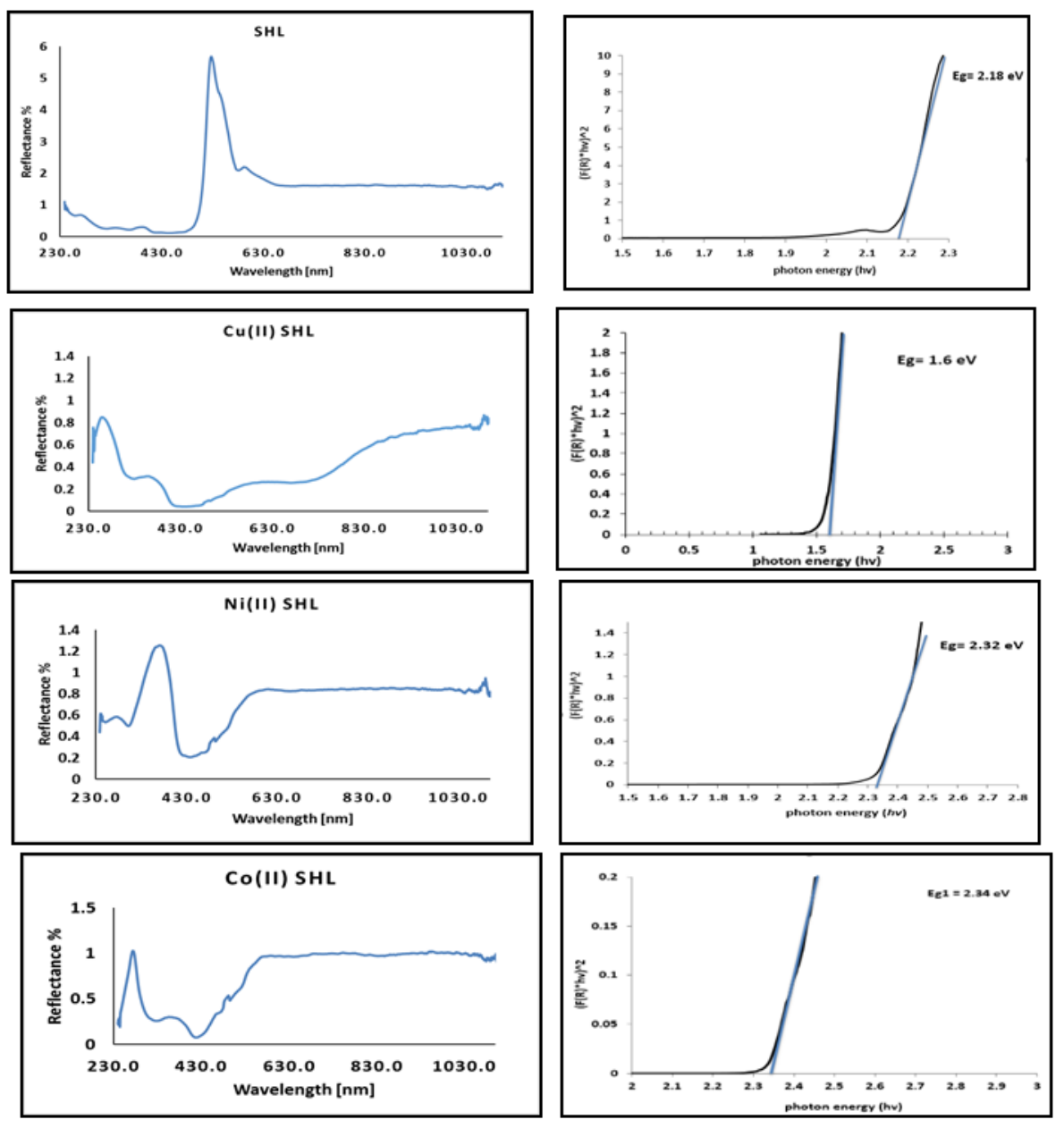

Figure 3 Reflectance and band energy gap of SHL and complexes

The energy gap of SHL was $2.18 \mathrm{eV}$, the complexes with a square planar geometry the energy gap was $1.6 \mathrm{eV}$ for $\mathrm{CuSHL}$ and $2.32 \mathrm{eV}$ for NiSHL, while in tetrahedral geometry the energy gap was $2.34 \mathrm{eV}$ for CoSHL, so it is a higher value compared with the other complexes; therefore the CoSHL complex will be less semiconductive. The CuSHL complex has the best semiconductive properties due to the small bandgap indicates to the easy electronic transitions from the HOMO to LUMO energy levels. ${ }^{24}$

\section{Surface morphology}

The Surface morphology properties measured by atomic force microscopy AFM, the 3D image of the surface morphology for SHL, and its complexes, see Figure 4. The 3D image of the surface shows that the Schiff base was irregular particle distribution while the complexes have a regular homogenous distribution appearance and the partial size scale. More regular 
homogenous distribution appearance in NiSHL complex and CoSHL particles form disklike and more diameters. Topography data are shown in Table 3. The surface roughness of NiSHL becomes very smooth than SHL this leads to increase light scattering and reflectance, then a high energy gap, while CoSHL, topography properties are high.
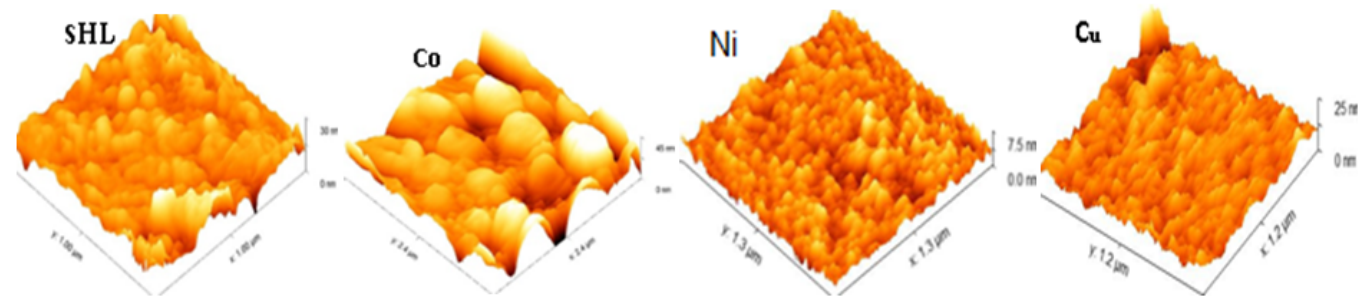

Figure 4 Surface morphology, 3D image of SHL and complexes.

Table 3 Topography properties of SHL and c mplexes.

\begin{tabular}{|c|c|c|c|c|}
\hline $\begin{array}{l}\text { Com- } \\
\text { plex }\end{array}$ & $\begin{array}{l}\text { RMS Surface } \\
\text { Roughness(nm) }\end{array}$ & $\begin{array}{l}\text { Average } \\
\text { Diameter(nm) }\end{array}$ & $\begin{array}{l}\text { Average } \\
\text { Height(nm) }\end{array}$ & $\begin{array}{l}\text { Average Size } \\
\left(\mathrm{nm}^{2}\right)\end{array}$ \\
\hline SHL & 3.29 & 18.58 & 17.81 & 271.08 \\
\hline CoSHL & 8.85 & 60.67 & 35.72 & 2890.50 \\
\hline NiSHL & 0.835 & 12.10 & 7.08 & 114.93 \\
\hline CuSHL & 2.34 & 23.40 & 14.50 & 429.90 \\
\hline
\end{tabular}

\section{Theoretical studies}

Hyper Chem 8.0.1 software and using semi-empirical calculations with the PM3 method to estimate the optimized molecular structure of the SHL and complexes, see Figure 5. All geometric structure is shown non-planar, and the coordination occurs between a metal with nitrogen and oxygen atoms. ${ }^{25}$

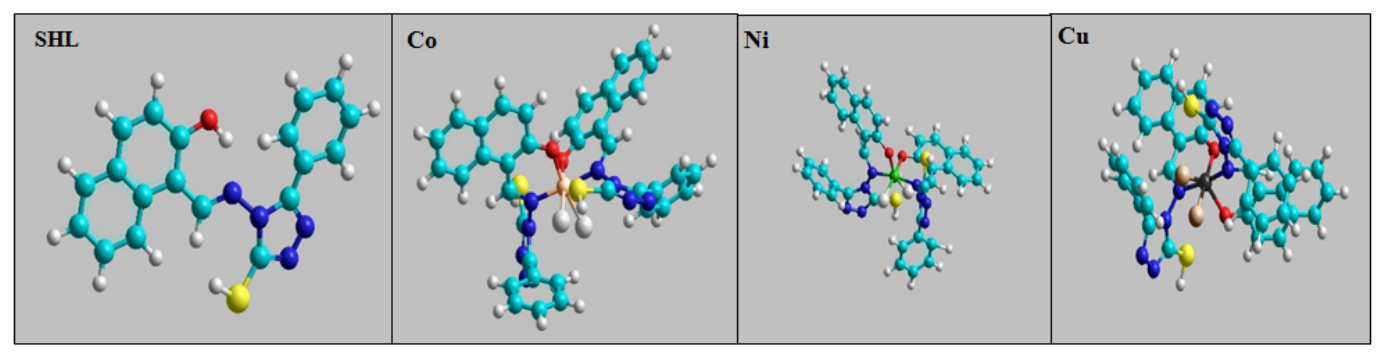

Figure 5 Optimized structure balls and cylinder shape of SHL and its c omplexes 


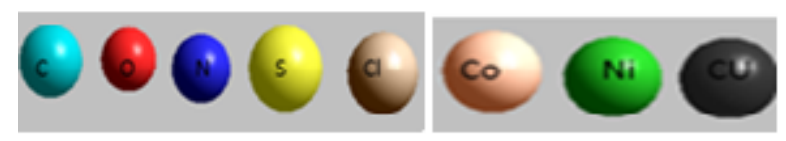

\section{Semi-conductive properties and electronic transition of molecular orbitals}

The stability of the structures and electrical transport properties determined in the theoretical study as an energy gap, which is the difference between the highest occupied molecular orbital (HOMO) and the lowest unoccupied molecular orbital (LUMO), (i.e. $\mathrm{E}_{g a p}=$ $\left.\mathrm{E}_{L U M O}-\mathrm{E}_{H O M O}\right)$.

The stability of the SHL and the complexes were shown when the energy gap calculation lower value that means the higher stability complex formed are shown in Figure 6, CoSHL complex has the highest energy gap $(\Delta \mathrm{E}=2.737 \mathrm{eV})$ that means the electron stay in a ground state level (lower energy) more than transition to the excited state (high energy). CuSHL complex was the energy gap $(\Delta \mathrm{E}=1.825 \mathrm{eV})$ and become more semi-conductive than other complexes. $^{26}$
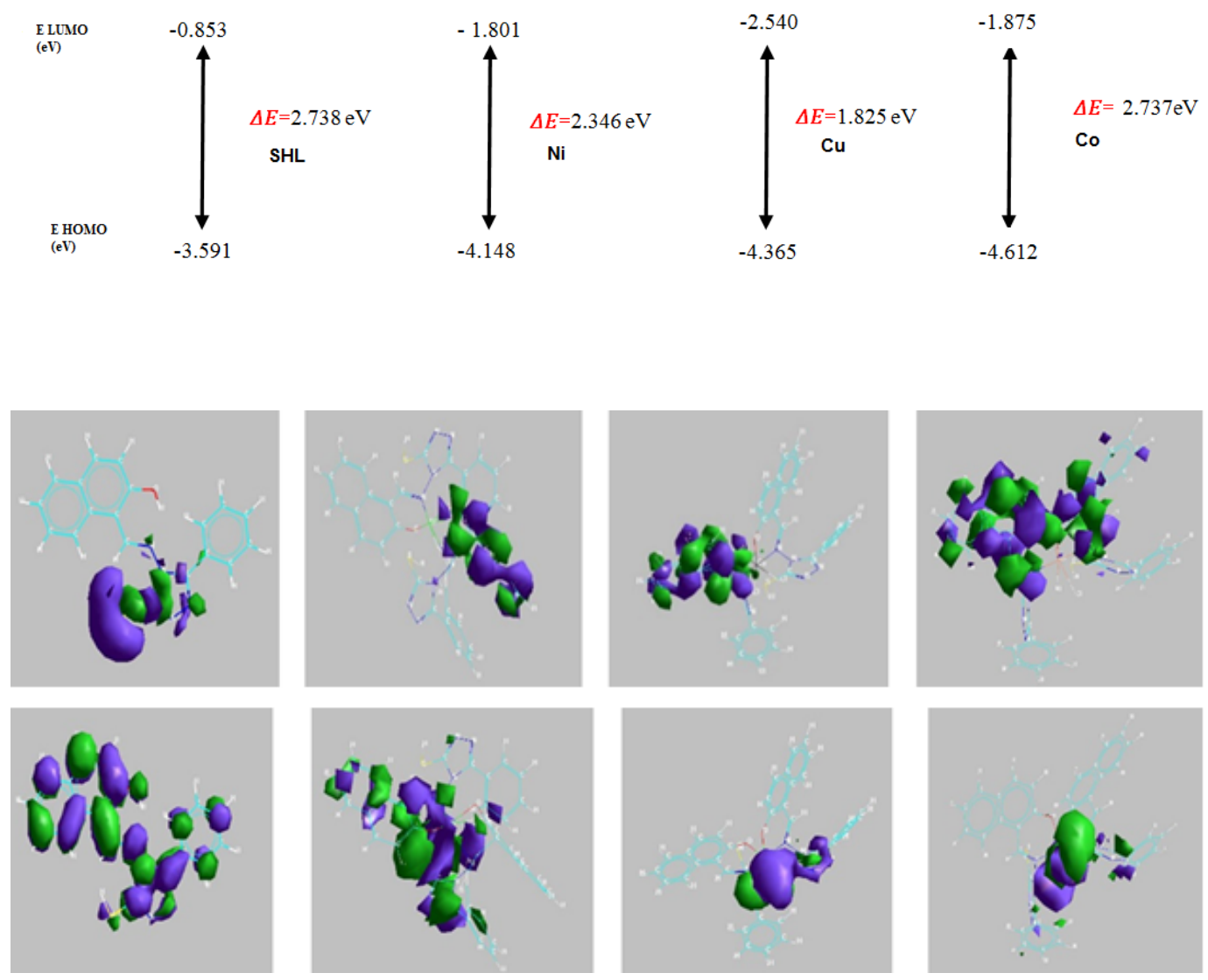

Figure 6 Frontier molecular orbitals of structures of SHL and its complexes 


\section{The effect of the coordination on bond length}

The theoretical study and the practical results from FTIR spectra show that the coordination occurs between metal ion and oxygen of phenolic group and nitrogen of imine group $(-\mathrm{C}=\mathrm{N}-)$ of the Schiff base ligand and the bond length effect as the metal used and the structural form. Table 4 and Figure 7 show that effected. The CuSL the bond length of $(-\mathrm{C}=\mathrm{N}-),(-\mathrm{C}-\mathrm{O}-)$ increases when compared with a free ligand.

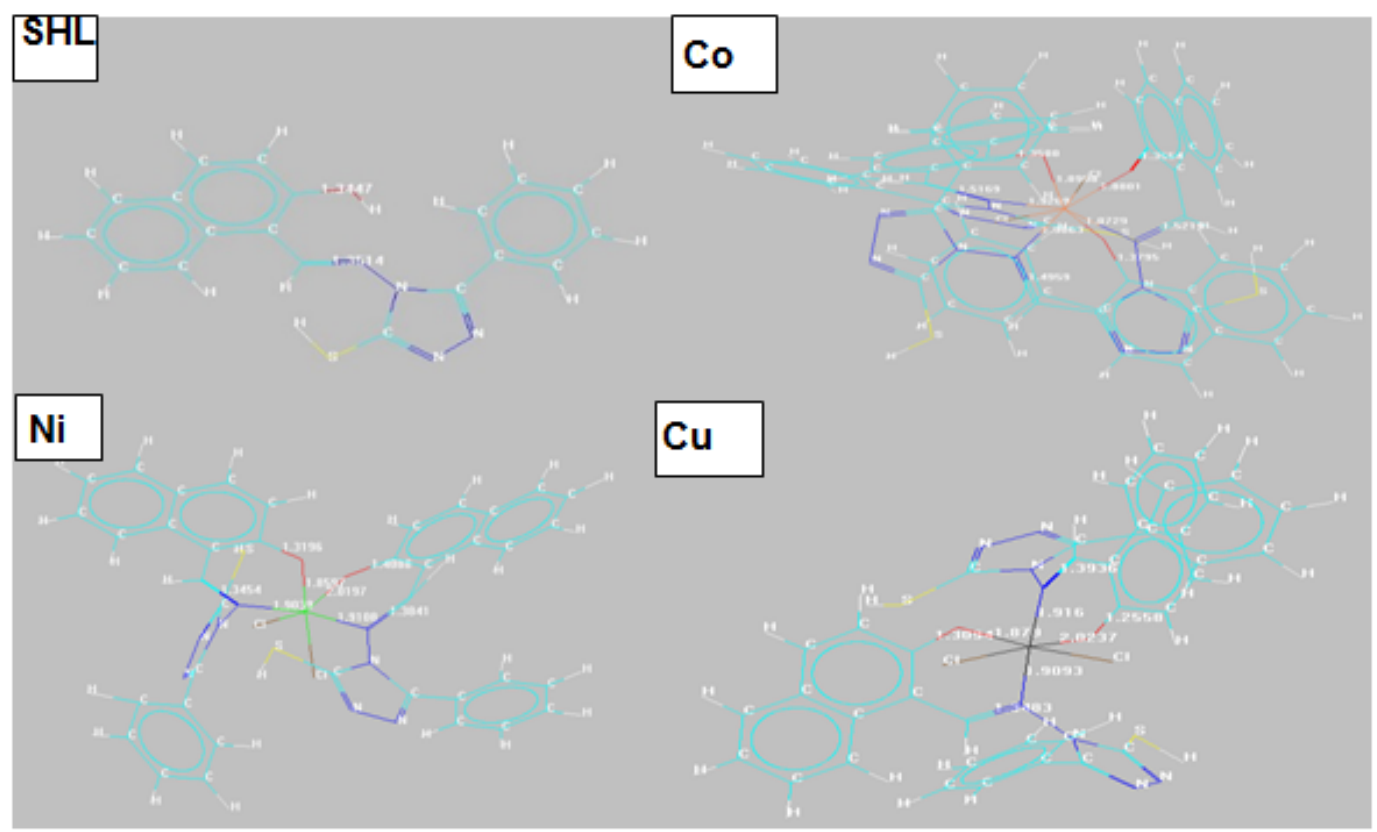

Figure 7 Some bonds lengths of Schiff base and complexes

\begin{tabular}{lllll}
\hline \multicolumn{5}{l}{ Table 4 Some bonds lengths of SHL and its complexes } \\
Compound & Metal-O & Metal -N & C=N & C-O \\
SHL & - & - & 1.3514 & 1.3447 \\
NiSHL & 2.0197 & 1.9108 & 1.3841 & \\
& 1.8597 & 1.9039 & 1.3454 & 1.2558 \\
CuSHL & 2.0237 & 1.916 & 1.3936 & 1.3094 \\
& 1.879 & 1.9093 & 1.3483 & 1.2954 \\
CoSHL & 1.8760 & 1.9287 & 1.3567 & 1.3011 \\
\hline
\end{tabular}

\section{CONCLUSION}

The Schiff base SHL was prepared successfully by condensation reaction between 4Amino-3-mercapto-5-phenyl-4H-1,2,4-triazole and 2-hydroxy-1-naphthaldehyde, the tri- 
azole Schiff base acts as a bidentate ligand through donor groups of phenolic and an imine and gave a good result compared with the theoretical calculation of bond length, especially $(-\mathrm{C}=\mathrm{N}-)$, (-C-O-) bonds, CuSHL complex has longer bond length. The geometry of the prepared complexes was proposed the CoSHL complex has a tetrahedral geometry, NiSHL, and CuSHL complexes have a square planar geometry according to spectroscopy measurements. The valence electrons of metal ion affect physical properties and gave the semiconductivity behaviour to the free ligand. From the calculating energy gap using diffuse reflectance spectroscopy and theoretical study, CuSHL complex is more semiconductive, which indicates the electronic transitions from the HOMO to LUMO energy levels were easy, the tetrahedral CoSHL complex was less semi-conductive, due to difficult electronic transitions between the energy levels. As well as, the surface morphology of SHL and its complexes appearance more regular homogeneous distribution in NiSHL and CoSHL complexes.

\section{ACKNOWLEDGMENTS}

The authors would like to thank the staff and head of the Department of Chemistry, College of Science, Al-Nahrain University for the support during the experimental work.

\section{DECLARATIONS}

\section{Authors' contributions}

All authors have equally contributed to this work.

\section{Conflict of interest}

The authors declare that there is no conflict of interest.

\section{Ethical approvals}

This work was conducted and approved by the Department of Chemistry, College of Science, Al-Nahrain University, Baghdad, Iraq.

\section{Data availability}

The data associated with this work can be requested from the corresponding author.

\section{Funding resources}

This work didn't receive any fund.

\section{REFERENCES}

1. Kuddushi M, Malek M, Patidar VL, Patel MS, Rk P, Article DRR. Int J Recent Sci Res. 2018;9:26026-26030. Available from: 10.24327/IJRSR. 
2. Kareem M, Salman, Synthesis A. Characterization and antimicrobial studies of transition metal complexes with Azo ligand derivative from 4- Aminoantipyrine. Mesopotemia Environ J. 2017;p. 83-91.

3. Mohanambal D, Aa S, Synthesis. Characterization and antimicrobial activity of some novel Schiff base 3d transition metal complexes derived from dihydropyrimidinone and 4-Aminoantipyrine. Res J Chem Sci. 2014;4(7):1-7.

4. Siddappa K, Mayana NS. Synthesis, spectroscopic characterization, and biological evaluation studies of 5-Bromo-3-(((hydroxy-2-methylquinolin-7yl)methylene)hydrazono)indolin-2-one and its metal (II) complexes. Bioinorg Chem Appl. 2014;2014:1-11. Available from: 10.1155/2014/483282.

5. Ahmad N, Anouar EH, Tajuddin AM, Ramasamy K, Yamin BM, Bahron H. Synthesis, characterization, quantum chemical calculations and anticancer activity of a Schiff base NNOO chelate ligand and Pd(II) complex PLoS One. 2020;15:1-17. Available from: 10.1371/journal.pone.0231147.

6. Ângelo de Fátima, de Paula Pereira C, Olímpio CRSDG, de Freitas Oliveira BG, Franco LL, da Silva PHC. Schiff bases and their metal complexes as urease inhibitors - A brief review. J Adv Res. 2018;13:113-126. Available from: 10.1016/j.jare.2018. 03.007.

7. Sakhare DT. Synthesis, characterization of schiff bases and biological activities of their transition metal complexes-review. Int J Adv Sci Eng. 2020;06(04):1538-1544. Available from: 10.29294/ijase.6.4.2020.1538-1544.

8. Boceiri N, Benabdallah T, Youcef MH, Reffas H. Synthesis and Characterization of a Novel Series of Amphiphilic Mercapto-1,2,4-Triazole Schiff Base Ligands: Investigation of their Behavior in Hydro-Organic Solutions. J Surfactants Deterg. 2016;19(3):583-597. Available from: 10.1007/s11743-016-1811-1.

9. Fonkui TY, Ikhile MI, Ndinteh DT, Njobeh PB. Microbial activity of some heterocyclic Schiff bases and metal complexes: A review. Trop J Pharm Res. 2019;17(12):2507-2518. Available from: 10.4314/tjpr.v17i12.29.

10. Ommenya FK, Nyawade EA, Andala DM, Kinyua J. Synthesis, characterization and antibacterial activity of Schiff base, 4-Chloro-2-\{(E)-[(4Fluorophenyl)imino]methyl\}phenol metal (II) complexes. J Chem. 2020;2020:1-8. Available from: 10.1155/2020/1745236.

11. Mohamed GG, Mahmoud WH, Diab MA, El-Sonbati AZ, Abbas SY. Synthesis, characterization, theoretical study and biological activity of Schiff base nanomaterial analogues. J Mol Struct. 2019;1181:645-659. Available from: 10.1016/j.molstruc.2019. 01.007 .

12. Ibrahim FM. Polyether hexadentate Schiff base ligand with trivalent chromium, iron, cobalt ions. J Al-Nahrain Univ Sci. 2017;20(4):1-6.

13. Bharati KT, Gujarathi DB, Tryambake PT, Hase GJ, Gaikwad RK, Khatal MB. Preparation of Schiff base of 1, 2, 4-Triazole-4-amine with 3-Nitrobenzaldehyde, its complexation with $\mathrm{Cu}$ (II) and Zn (II) and antimicrobial activity of complexes. Der Chem Sin. 2017;8(2):223-231. 
14. Ahmed AA, Ahmed DS, El-Hiti GA, Alotaibi MH, Hashim H, Yousif E. SEM morphological analysis of irradiated polystyrene film doped by a Schiff base containing a 1,2,4-triazole ring system. Appl Petrochem Res. 2019;9:169-177. Available from: 10.1007/s13203-019-00235-6.

15. Modi JA, Desai KR, Lokhandwala SR. Synthesis of Novel 1, 2, 4-Triazoles and their Schiff Base Derivatives and Evaluating their Antimicrobial Activity. World J Pharm Pharm Sci. 2014;3(3):1875-85.

16. Ali AA, Bi AA. triazole-4-yl ) imino ) methyl ) -2-methoxyphenol and its complexes with Zr ( IV ), Cd ( II ) and Sn ( II ) ions. Iraqi J Sci. 2015;56(2):1274-88.

17. Gaber M, El-Ghamry HA, Fathalla SK. Ni(II), Pd(II) and Pt(II) complexes of $(1 \mathrm{H}-$ 1,2,4-triazole-3-ylimino)methyl]naphthalene-2-ol. Structural, spectroscopic, biological, cytotoxicity, antioxidant and DNA binding. Spectrochim Acta A Mol Biomol Spectrosc. 2015;139:396-404. Available from: 10.1016/j.saa.2014.12.057.

18. V NR, Tr P, Angadi SD, Synthesis. Synthesis, characterization and biological activities of $\mathrm{Cu}(\mathrm{II}), \mathrm{Co}(\mathrm{II}), \mathrm{Ni}(\mathrm{II}), \mathrm{Mn}(\mathrm{II})$ and $\mathrm{Fe}(\mathrm{III})$ complexes with Schiff base derived from 3-(4-Chlorophenoxymethyl)-4-amino-5-mercapto-1,2,4-triazole. J Chem. 2008;5(3):529-567. Available from: 10.1155/2008/690535.

19. Tyagi P, Tyagi M, Agrawal S, Chandra S, Ojha H, Pathak M. Synthesis, characterization of 1,2,4-triazole Schiff base derived 3d- metal complexes: Induces cytotoxicity in HepG2, MCF-7 cell line, BSA binding fluorescence and DFT study. Spectrochim Acta A Mol Biomol Spectrosc. 2017;171:246-257. Available from: 10.1016/j.saa.2016.08.008.

20. Nagaveni VB, Mahadevan KM, Vijayakumar GR, Nagabhushana H, Naveen S. Synthesis , crystal structure and excellent photoluminescence properties of copper (II) and cobalt (II) complexes with Bis. J Sci Adv Mater Devices. 2018;3(1):51-59. Available from: 10.1016/j.jsamd.2018.01.001.

21. Ahmed AA, Ahmed DS, El GA, Mohammad H, Alotaibi H, Hashim H. SEM morphological analysis of irradiated polystyrene film doped by a Schiff SEM morphological analysis of irradiated polystyrene film doped by a Schiff base containing a 1 , 2 , 4 - triazole ring system. Appl Petrochemical Res. 2019; Available from: 10.1007/s13203-019-00235-6.

22. Agalave SG, Maujan SR, Pore VS. Click chemistry: 1,2,3-triazoles as pharmacophores. Chem Asian J. 2011;6(10):2696-718. Available from: 10.1002/asia. 201100432.

23. Nagaveni VB, Mahadevan KM, Vijayakumar GR, Nagabhushana H, Naveen S, Lokanath NK. Synthesis, crystal structure and excellent photoluminescence properties of copper (II) and cobalt (II) complexes with Bis(1[(4-butylphenyl)imino]methyl naphthalen-2-ol) Schiff base. J Sci Adv Mater Devices. 2018;3(1):51-58. Available from: 10.1016/j.jsamd.2018.01.001.

24. Stan CS, Horlescu P, Sutiman D, Mita C, Peptu C, Fortuna ME, et al. New complexes of 2-(1H-1, 2, 4-Triazol-3-YL) pyridine with $\mathrm{Co}(\mathrm{II}), \mathrm{Cd}(\mathrm{II}), \mathrm{Rh}(\mathrm{III})$, ions: Synthesis, structure, properties, and potential applications. Environ Eng Manag J. 
2015;14(2):389-397. Available from: 10.30638/eemj.2015.040.

25. Jber NR, Rashad AA, Shihab MS. Effects of carbon nanotubes on the physical properties of a nematic liquid crystal $\mathrm{N}$-( $4^{\prime}$-methoxybenzylidene)-4-butylaniline. J Mol Struct. 2013;1043:28-36. Available from: 10.1016/j.molstruc.2013.03.056.

26. Islam MJ, Zannat A, Kumer A, Sarker N, Paul S, Zannat A. The prediction and theoretical study for chemical reactivity, thermophysical and biological activity of morpholinium nitrate and nitrite ionic liquid crystals: A DFT study. Adv J Chem A. 2019;2(4):316-326. Available from: 10.33945/SAMI/AJCA.2019.4.5. 